\title{
Os cenários mundiais de negociações multilaterais antes da rodada Uruguai e o novo protecionismo do Pós-Guerra
}

\author{
World Scenarios of Multinational Negotiations Before the Uruguay Round and \\ the New Post-War Protectionism
}

Los escenarios mundiales para las negociaciones multilaterales antes de la Ronda Uruguay y el nuevo proteccionismo de posguerra

Olímpio de Arroxelas Galvão ${ }^{1}$

\section{Resumo}

GALVÃO. Olímpio de arroxelas. Os cenários mundiais de negociações multilaterais antes da rodada Uruguai e o novo protecionismo do Pós-Guerra. Rev. C\&Trópico, v. 43, n. 2, p. 11-28, 2019. DOI: https://doi.org/10.33148/Cetropicov43n2(2019)art.1

O trabalho descreve os principais cenários mundiais de negociações multilaterais antes da finalização da Rodada Uruguai, em 1994, e da criação da Organização Mundial do Comércio (OMC/WTO), em 1995. O foco da pesquisa é uma apreciação da evolução e dos desdobramentos das sete primeiras rodadas promovidas pelo antigo Secretariado do GATT (Acordo Geral sobre Tarifas e Comércio). $\mathrm{O}$ estudo procura ressaltar que o protecionismo praticado pelos países industrializados, tanto na esfera agrícola quanto na industrial, teria funcionado como um forte impeditivo à adoção de políticas alternativas, da parte dos países em desenvolvimento, baseadas em crescimento via exportações.

Palavras-chave: rodadas multilaterais de negociações. GATT. Países em desenvolvimento. O "novo" mercantilismo do Pós-Guerra.

\section{Abstract}

GALVÃO. Olímpio de arroxelas. World Scenarios of Multinational Negotiations Before the Uruguay Round and the New Post-War Protectionism. Rev. C\&Trópico, v. 43, n. 2, p. 11-28, 2019. DOI: https://doi.org/10.33148/Cetropicov43n2(2019)art.1

This paper analyses the main world scenarios of multilateral negotiations before the end of the Uruguay Round, in 1994, and the creation of the WTO, in 1995. The focus of the research is an evaluation of the evolution and developments of the seven first Rounds undertaken by the old GATT Secretariat. The study tries to emphasize that the protectionism adopted by the industrialized countries, both in the agricultural as well as in the industrial sphere, would have worked as a strong obstacle to the adoption of alternative policies, on the part of the developing countries, based on export-led growth.

Ph.D em Economia, University College da Universidade de Londres, UK (1988); Mestre em Economia, Universidade de Yale, Conn.,USA (1970); atualmente, professor Titular da Faculdade Boa Viagem/DeVry. Email: olimpio.galvao@gmail.com 
Keywords: Multilateral Trade Negotiations. GATT. Developing countries. The "new" mercantilism of the post-world war.

\section{Resumen}

GALVÃO. Olímpio de arroxelas. Los escenarios mundiales para las negociaciones multilaterales antes de la Ronda Uruguay y el nuevo proteccionismo de posguerra. Rev. CઐTrópico, v. 43, n. 2, p. 11-28, 2019. DOI: https://doi.org/10.33148/Cetropicov43n2(2019)art.1

El documento describe los principales escenarios mundiales para las negociaciones multilaterales antes de la conclusión de la Ronda Uruguay, en 1994, y de la creación de la Organización Mundial del Comercio (OMC/WTO), en 1995. El foco de la investigación es una apreciación de la evolución de los desarrollos de las primeras siete rondas promovidas por la antigua Secretaría del Acuerdo General sobre Aranceles Aduaneros y Comercio- GATT. El estudio busca enfatizar que el proteccionismo practicado por los países industrializados, tanto en la esfera agrícola como industrial, habría actuado como un fuerte impedimento para la adopción de políticas alternativas por parte de los países en desarrollo, basadas en el crecimiento a través de las exportaciones.

Palabras clave: Rondas multilaterales de negociaciones. GATT. Paises en desarrollo. El nuevo mercantilismo de posguerra.

\section{Introdução}

Este trabalho propõe uma breve avaliação do cenário mundial de negociações antes da criação da Organização Mundial do Comércio (OMC/WTO), em 1995, demonstrando as dificuldades dos países em desenvolvimento nas suas negociações com o Secretariado do Acordo Geral sobre Tarifas e Comércio (GATT) e como, ao longo do tempo, esse Acordo foi incorporando algumas demandas desses países por um tratamento especial nas suas relações com os países industrializados. Na seção a seguir, que cobre o período 1947-1961, examinam-se os desdobramentos das primeiras cinco rodadas multilaterais de negociações. Na terceira seção, descreve-se o florescimento de uma onda de protecionismo comercial, que emerge a partir dos anos 70, destacando-se os esforços dos países em desenvolvimento para obterem concessões especiais das nações industrializadas, ao longo das duas rodadas seguintes de negociações, que ocorreram antes da Rodada Uruguai. Uma seção final apresenta as conclusões.

\section{O período 1947-1961: os países em desenvolvimento du- rante as cinco primeiras rodadas de negociações do GATT}

A criação do GATT, no ano de 1947, foi festejada como um acontecimento de enorme significação no pós-guerra, por ter introduzido, pela primeira vez, um conjunto de regras e disciplinas no comércio mundial. Numa época em que predominavam ações unilaterais dos governos, seguidas de correspondentes retaliações de outras nações, o resultado da inexistência de um corpo de leis comerciais, aplicáveis 
em escala internacional, era a ocorrência de constantes turbulências diplomáticas, acirradas disputas por mercados e um forte impacto negativo sobre o crescimento dos fluxos mundiais de negócios. Além do mais, o GATT propiciou, mesmo que precariamente, a criação de um mecanismo de consultas e de solução de controvérsias, que operava como um fórum no qual os países, com interesses divergentes, podiam discutir as suas diferenças e firmar compromissos e obrigações, relativos à esfera das relações comerciais.

$\mathrm{Na}$ visão dos analistas dos países menos desenvolvidos, o GATT, todavia, funcionou, durante muitas décadas, como um instrumento quase que inteiramente voltado para os interesses dos países industrializados e, especialmente, os das nações econômica e politicamente mais poderosas ${ }^{2}$.

No documento base de 1947, apenas incidentalmente o GATT fazia referência a um tratamento especial aos países menos desenvolvidos e, mesmo assim, somente permitindo a continuidade dos acordos parciais de preferências comerciais pré-existentes, entre países industrializados e atrasados, como os que operavam dentro do sistema da Commonwealth britânica e os que ligavam a França a algumas de suas colônias ou ex-colônias - mas proibia, enfaticamente, a assinatura de novos acordos que pudessem vir a oferecer ou expandir vantagens preferenciais a outras nações menos desenvolvidas (WTO/GATT 47, Art. $1^{\circ}$ e Art. XXIV).

Eram muitas as queixas dos representantes das nações menos desenvolvidas. Raul Prebisch, que ocupava, no início dos anos 1960, o posto de Secretário Geral da Conferência das Nações Unidas sobre o Comércio e o Desenvolvimento (UNCTAD), assinalava que o GATT, tanto na sua versão de 1947, quanto nas diversas emendas que esse Acordo sofreu após várias rodadas de negociações, não dispensava qualquer consideração aos problemas dos países subdesenvolvidos (PREBISH, 1964, p.6). No seu relatório preparado sob os auspícios das Nações Unidas e como Secretário Geral da primeira UNCTAD, de 1964, Prebisch afirmava que, por se partir de uma equivocada suposição de que os países signatários do Acordo Geral eram homogêneos, não havia, entre os artigos do GATT, qualquer dispositivo que estabelecesse uma distinção entre países desenvolvidos e em desenvolvimento (PREBISH, 1964, p. 29).

Com efeito, o GATT condenava explicitamente todo arranjo de caráter bilateral ou multilateral que implicasse alguma forma de facilitação privilegiada de acesso aos mercados das Partes Contratantes (como eram chamados os países signatários do GATT), não importando as diferenças existentes nos seus níveis de desenvolvimento.

A proibição de tratamento privilegiado às nações menos desenvolvidas estava explicitada em dois princípios considerados como basilares no Acordo Geral de 1947: o da reciprocidade - que exigia total simetria nas relações comerciais entre os países - e o da não-discriminação - que consistia na aplicação da cláusula de nação mais favorecida (NMF/MFN), que obrigava que qualquer concessão comercial de uma parte contratante a um país, teria de ser automaticamente estendida a todos os demais países.

\footnotetext{
2 Um Relatório do Banco Mundial, de 2005, reconheceu, de forma explícita, que o "sistema de comércio existente servia principalmente aos interesses dos países desenvolvidos” (WORLD BANK, 2005, p.212).
} 
A combinação do princípio da reciprocidade com o da não-discriminação, trazia duas claras implicações: gerava a total impossibilidade da melhoria das oportunidades de exportações dos países menos desenvolvidos, dentro das linhas estabelecidas pelo Acordo Geral (por não serem estes capazes de oferecer total simetria nas suas relações comerciais, em vista das fragilidades de suas economias) e tornava as ações do GATT inteiramente dependentes das políticas comerciais e dos interesses das nações industrializadas.

Os representantes dos países subdesenvolvidos procuravam demonstrar, perante a comunidade dos países industrializados, que havia uma profunda desigualdade econômica entre os países e que essa desigualdade tornava o princípio da simetria altamente injusto quando aplicado a economias desiguais. Não é por outra razão que o número de países signatários do GATT fosse tão pequeno, durante as primeiras décadas de existência desse Acordo, porque a grande maioria dos países menos desenvolvidos não via vantagens concretas em ingressar numa organização reguladora do comércio que pouco zelava pelos interesses dessas nações.

Vale observar que, no ano de 1947, quando da assinatura da Carta de Havana, após reunião sobre comércio e desenvolvimento, promovida pela ONU, com a presença de cerca de 100 países, ao tempo em que também era criado o GATT, somente 23 países subscreveram este Acordo Geral, entre os quais o Brasil. Apenas depois de várias rodadas de negociações, outros países foram, progressivamente, subscrevendo o GATT, na medida em que mudanças nas regras deste Acordo eram realizadas, por pressões dos países em desenvolvimento.

Além das queixas, de ordem geral, relativas à alegada injustiça para com as nações menos desenvolvidas, da aplicação dos princípios da reciprocidade e da não-discriminação, várias outras questões de grande interesse dos países em desenvolvimento foram levantadas ao longo das décadas de 1950 e 1960, durante as negociações comerciais que ocorriam sob a gestão do Secretariado do GATT. As principais críticas a este acordo centravam-se em três ordens de problemas: a concentração nas negociações do GATT no comércio de bens industrializados (quase que privilegiando apenas as relações comerciais entre os países desenvolvidos); o tratamento diferencial dispensado à agricultura (que favorecia práticas protecionistas às atividades agrícolas nos países industrializados); e o protecionismo a alguns setores industriais do mundo desenvolvido, principalmente os intensivos em mão de obra (que eram aqueles nos quais os países menos desenvolvidos tinham maiores chances de conquistar mercados externos).

Os representantes dos países em desenvolvimento alegavam que as cinco primeiras rodadas de negociações multilaterais do GATT, ocorridas entre o período de 1947 a $1961^{3}$, contribuíram para reduzir tarifas e outras restrições ao comércio mundial de produtos manufaturados, mas que essas negociações terminaram por beneficiar quase que exclusivamente os países industrializados, porque as exportações de manufaturados dos países menos desenvolvidos representavam uma diminuta fração

\footnotetext{
3 As cinco negociações comerciais multilaterais realizadas pelo GATT no período 1947-1961 foram as seguintes: a Rodada Genebra, em 1947, a de Annecy, em 1949, a de Torquay, em 1950-51, a Segunda Rodada Genebra, no biênio 1955-56 e a de Dillon, em 1960-61.
} 
do comércio internacional desses produtos. Apesar de se reconhecer que o aumento dos fluxos comerciais propiciado por essas negociações trazia uma contribuição indireta aos países em desenvolvimento, por elevar a renda dos países industrializados e, consequentemente, suas importações, o GATT era acusado de negligenciar os países em desenvolvimento nas duas áreas que mais afetavam os seus interesses: o comércio de bens primários (agrícolas e minerais) e o de certos bens industrializados nos quais as nações menos desenvolvidas poderiam encontrar fonte importante de geração de divisas (PREBISCH, 1964; JOHNSON, 1968).

No tocante à agricultura, as críticas à atuação do GATT se dirigiam principalmente à permissividade desta instituição para com certas práticas protecionistas aos produtores de bens primários nas economias industrializadas.

Por não conter regras explícitas regulando o comércio de commodities e manifestando certa indulgência com a aplicação de subsídios e outras políticas de suporte à agricultura ${ }^{4}$, o GATT, indiretamente, abriu o caminho para que as nações desenvolvidas buscassem a autossuficiência agrícola, fazendo com que, em pouco tempo, após a Segunda Grande Guerra, as nações europeias e os Estados Unidos, ao se tornarem grandes produtores e exportadores de commodities (em larga medida por conta dos generosos subsídios concedidos pelos seus governos), passassem a ver a criação de fortes lobbies de interesses contrários à liberalização do comércio mundial de bens agrícolas.

Ao longo dos anos 1950 e, sobretudo, dos anos 1960, as políticas comerciais dos países industrializados introduziram crescentes mecanismos de restrição às importações de bens agrícolas provenientes dos países subdesenvolvidos. Essas restrições cobriam praticamente todos os bens exportáveis pelos países menos desenvolvidos, afetando inclusive os produtos de origem tipicamente tropical, ou seja, aqueles que, por razões naturais ou climáticas, não poderiam ser produzidos nas nações industrializadas (como café, cacau, bananas e alguns minérios não existentes nesses países) - de sorte que as importações de bens agrícolas dos países menos desenvolvidos terminavam por alcançar, em muitos casos, níveis apenas residuais.

As barreiras levantadas ao comércio de commodities eram as mais variadas e diferiam largamente em função do produto e da natureza do seu processamento.

$\mathrm{O}$ argumento, na época, de que as nações industrializadas se especializavam em produtos agrícolas de clima temperado e que a produção desses produtos, portanto, impactava pouco as exportações dos países em desenvolvimento, era julgado improcedente pelos representantes das nações menos desenvolvidas, que alegavam que os produtos temperados produziam profundos efeitos negativos, tanto diretos quanto indiretos, sobre a produção e exportação dos países de clima tropical. Seja porque muitos

\footnotetext{
4 O GATT, na sua versão de 1947 e em emendas sofridas ao longo dos anos 1950/60, estabelecia, no seu artigo XVI, a proibição de subsídios sobre produtos manufaturados nos países desenvolvidos, mas permitia a concessão de subsídios e a utilização de medidas de suporte de preços ao setor agrícola desses países, sob o argumento de que tais políticas eram importantes para se alcançar relevantes objetivos sociais e econômicos. Embora o GATT estabelecesse alguns limites a essas práticas (em geral, de forma vaga), tais concessões exerceram o efeito de deflagrar uma proliferação de mecanismos de promoção e de proteção à agricultura nos países industrializados, cuja negociação, para que fossem abolidos ou reduzidos, se tornou, com o tempo, assunto de enormes disputas nos fóruns internacionais (WTO/GATT 1947, art. XVI; BHAGWATI (1988), LAIRD (1997).
} 
produtos temperados serviam de substitutos para produtos tropicais, seja porque muitos outros eram produzidos igualmente nos dois hemisférios, o impacto das políticas discriminatórias dos países industrializados era considerado devastador sobre o potencial agrícola das nações menos desenvolvidas. Vários exemplos eram mencionados nas rodadas de negociações: frutas temperadas competiam com frutas tropicais, as primeiras reduzindo ou deslocando o consumo das últimas; o açúcar de beterraba competia com o açúcar de cana e diminuía o consumo desta commodity, deprimindo os seus preços nos mercados mundiais; o algodão, o milho, os óleos vegetais, o fumo, o arroz, as carnes, os produtos lácteos, vários outros cereais, vegetais e diversos produtos de origem mineral, eram produzidos igualmente nos dois hemisférios, em grandes quantidades. A proposta era tornar cada vez mais difícil a entrada de produtos primários nos mercados dos países desenvolvidos, fossem eles de origem tipicamente tropical ou não, por conta das elevadas taxações e restrições quantitativas que sobre os mesmos incidiam, ou ainda pela incapacidade de as nações menos desenvolvidas competirem com os preços subsidiados dos bens agrícolas das nações industrializadas (JOHNSON,1968; PREBISCH, 1964).

Outro efeito negativo que as políticas comerciais dos países desenvolvidos exerciam sobre os mais atrasados era a aplicação, a partir do ano 1954, da Public Law 480, aprovada pelo Congresso dos Estados Unidos - uma lei que autorizava o governo desse país a exportar seus excedentes de grãos e de outros produtos primários, a preços menores que os do mercado internacional. Vários analistas dessa política mostravam que o seu efeito era o de deprimir o preço das commodities produzidas pelos outros países em desenvolvimento ou até mesmo de excluí-los como supridores de uma fração significativa dos mercados mundiais de alimentos ${ }^{5}$.

Os países desenvolvidos ainda usavam de outros expedientes que operavam largamente em desfavor da agricultura e da agroindústria das nações em desenvolvimento. A proteção aos setores primários daqueles países variava de acordo com a natureza do processamento dos produtos primários. Bens exportados em forma bruta (alimentos, minérios, fibras, etc.), sofriam tarifação mais baixa, mas as tarifas se elevavam na medida em que tais bens recebiam algum processamento - de tal sorte que, quanto mais valor era agregado ao produto primário, mais elevados os impostos sobre suas importações - caracterizando um mecanismo chamado de "tariff escalation", ou de tarifas moduladas, e que conferia às indústrias dos países desenvolvidos, uma proteção efetiva muito maior do que indicavam as tarifas nominais impostas por esses países. $\mathrm{O}$ efeito dessas práticas era, obviamente, o de manter os países subdesenvolvidos especializados na produção e exportação de produtos primários não beneficiados e, consequentemente, de inibir as iniciativas de industrialização, julgadas tão importantes pelas nações menos desenvolvidas, não somente para livrá-las da dependência da produção de uns poucos bens primários e de promover um processo de diversificação

\footnotetext{
Análises quantitativas dos impactos negativos da Public Law 480 sobre a agricultura dos países subdesenvolvidos foram feitas especialmente pelo respeitado economista agrícola norte-americano, D. Gale Johnson, em seu artigo "Agriculture and Foreign Economic Policy", publicado no Journal of Farm Economics, vol. 46, de dezembro de 1964 (Apud JOHNSON, 1968, pp. 86 e 92)
} 
de suas pautas de exportações, mas como um instrumento poderoso de geração de emprego e renda nas suas economias ${ }^{6}$.

Outro aspecto fortemente criticado no GATT, ainda em referência ao seu trato com a agricultura, era a aceitação da violação de alguns princípios básicos do Acordo Geral sobre preferências comerciais, o que passou, com o tempo, a exercer significativos impactos negativos sobre um vasto número de economias em desenvolvimento, com destaque especial para as nações latino-americanas e o Brasil.

Como já assinalado anteriormente, o Art. $1^{\circ}$ do GATT proibia o uso de tarifas preferenciais, por contrariarem a cláusula de nação-mais-favorecida e, consequentemente, o princípio da não-discriminação. Esse artigo, como já sugerido, obrigava a multilateralização automática das condições de tratamento mais favorável, concedidas bilateralmente entre dois ou mais Estados, ao universo das partes contratantes. Mas, por pressão de alguns países industrializados da Europa, foi introduzido um artigo no Acordo Geral de 1947 - o Art. XXIX - que permitia não somente a continuidade dos arranjos de preferências comerciais pré-existentes ao GATT, mas também, a assinatura de novos acordos, desde que inseridos dentro de esquemas voltados para a formação de áreas de livre comércio ou de uniões aduaneiras (WTO/GATT 1947).

Além da existência dos velhos arranjos de preferências comerciais praticados na Commonwealth britânica e pela França com algumas de suas colônias, só havia, pouco antes da assinatura do GATT, um caso único de integração comercial entre os países: o formado pelas pequenas nações europeias da Bélgica, Holanda e Luxemburgo, chamado de BENELUX - que consistia numa ainda modesta experiência de união aduaneira. Por conta dessas experiências pré-existentes ao GATT, os relatores da primeira versão desse Acordo Geral resolveram estabelecer como uma exceção à cláusula de nação-mais-favorecida, a permissão, no referido artigo XXIV, da existência de áreas de livre comércio e de uniões aduaneiras, por acreditarem que essas iniciativas contribuiriam para aumentar a liberdade de comércio - mesmo que em áreas geográficas limitadas. Esse artigo, ao tempo em que estimulava processos integracionistas, estabelecia, porém, que as iniciativas de formação de blocos regionais de comércio não poderiam servir de fortalezas protecionistas, desviando comércio de terceiros países fora dos blocos, operando, assim, em detrimento de outras nações.

Quando da formação do seu Mercado Comum, no final dos anos 1950, a Comunidade Econômica Europeia (CEE), tratou logo de instituir uma tarifa externa comum (a TEC), que deveria ser, em princípio, aplicável em bases não discriminatórias,

\footnotetext{
Durante os anos 1960, ainda eram poucos os estudos que procuravam estimar os efeitos da aplicação de tarifas moduladas (o mecanismo de tariff escalation) sobre as exportações de bens primários e commodities pelos países menos desenvolvidos. Um estudo mencionado por Johnson revela algumas poucas estimativas que mostram as dificuldades com que se defrontavam as nações exportadoras de primários para beneficiarem os seus produtos, em vista da tarifação elevada que, na prática, prevalecia sobre tais produtos beneficiados. Os seguintes exemplos servem de ilustração para mostrar como eram fortemente penalizadas as tentativas de industrialização de bens primários quando destinados ao mercado internacional: enquanto a tarifa nominal sobre importações de óleo de coco refinado era de apenas 5,7\% e de 15\%, nos Estados Unidos e na Comunidade Econômica Europeia, respectivamente, a tarifa efetiva de proteção se elevava para $57,5 \%$ e para $150 \%$, nos dois grupos de países. Para fumo beneficiado, as cifras respectivas para os Estados Unidos eram de $47,2 \%$ e $89 \%$, e para fibras naturais processadas, de $15,1 \%$ para $38 \%$ (JOHNSON, 1968, p. 91, Tabela 2).
} 
a todos os países não membros dessa comunidade. Mas já no início dos anos 1960, a CEE começou a firmar uma série de arranjos comerciais, nos quais diferentes grupos de países eram tratados de forma diferenciada. Ao longo do tempo, a Comunidade Europeia foi ampliando seus esquemas de preferências comerciais, estendendo-os a mais regiões e países com os quais os europeus desejavam manter relações especiais de comércio. Esses arranjos, firmados por meio das várias Convenções de Lomé, e que abrigavam algumas dezenas de países da África, da Ásia e do Caribe (denominados de ACP), abrangiam tanto concessões na área agrícola, quanto na de produtos industrializados.

Tais sistemas parciais de preferências comerciais vigentes nos anos 1960 eram criticados no GATT por grande número de países em desenvolvimento, exatamente pelas suas características de não multilateralidade, ou seja, sob a alegação de que favoreciam alguns países, às expensas de outros, e também de que estariam provocando mais desvio de comércio do que criação de novos fluxos comerciais ${ }^{7}$ (PREBISCH, 1964, p. 8).

Embora nos meados dos anos 1960 as exportações de produtos primários representassem cerca de $85 \%$ do total das receitas cambiais dos países menos desenvolvidos (JOHNSON, 1968, p. 84), o comércio de bens semimanufaturados e manufaturados já assumia importância crescente para um grande número desses países - os quais, igualmente ao que faziam com relação aos bens primários, criticavam severamente o GATT, por essa organização não se empenhar em impedir que elevadas barreiras tarifárias e outras restrições quantitativas fossem impostas pelos países desenvolvidos.

Com efeito, também na esfera do comércio de bens manufaturados, e particularmente daqueles onde residiam as maiores vantagens comparativas das nações em desenvolvimento - como têxteis, artigos de vestuário e confecções, calçados, produtos alimentares processados e diversos bens duráveis leves de consumo, como alguns produtos elétricos e eletrônicos, bicicletas e máquinas de costura - os países industrializados erguiam barreiras crescentes à importação, e o GATT era acusado de agir com total indiferença em relação às demandas das nações em desenvolvimento.

A questão do comércio de manufaturados era ainda mais agravada, porque também no seu caso, era aplicado o mesmo esquema de tarifas moduladas que eram praticadas contra o processamento de bens primários. Os produtos de pouca elaboração industrial eram tributados com uma alíquota menor (caso dos bens intermediários), alíquota que ia se elevando com o grau de processamento final do bem (fios de algodão pagavam tarifas menores, tecidos tarifas maiores e confecções ainda mais elevadas, por exemplo) - mais uma vez trazendo, como consequência, o dificultamento de iniciativas de industrialização nos países menos desenvolvidos, mesmo que fossem naquelas linhas reconhecidamente consistentes com as vantagens comparativas dessas nações.

\footnotetext{
Os principais produtos exportados pelos países do ACP eram: petróleo e derivados, café, açúcar, arroz, diversos outros cereais, carnes, cacau, bananas, farelo para rações, cobre refinado, madeiras, ferro e aço, diamante, produtos têxteis e artigos de vestuário - um conjunto, portanto, de muitos produtos importantes da pauta de exportações do Brasil que tinham de enfrentar, assim, dificuldades muito maiores para penetração nos mercados da então CEE.
} 
Ademais, sempre que alguns poucos países conseguiam superar as barreiras existentes, novas barreiras iam sendo criadas, sob a alegação de que tais importações destruíam, ou ameaçavam destruir, as indústrias domésticas dos países industrializados, que deveriam, assim, ser protegidas por medidas de salvaguardas.

Vale ressaltar que o GATT previa que um país poderia se defender contra importações competitivas que causassem, ou pudessem vir a causar, danos às suas indústrias, mas apenas sob duas condições: por motivos de desequilíbrios no balanço de pagamentos ou por provocarem elevação no desemprego, quando este se encontrasse em nível já elevado. Mas, raras vezes, eram esses problemas que realmente levavam os países industrializados a protegerem, tanto a sua agricultura, quanto as suas indústrias domésticas, da concorrência das nações menos desenvolvidas.

Com efeito, as leis vigentes nos Estados Unidos, por exemplo, permitiam explicitamente um aumento das tarifas norte-americanas, sem que houvesse necessidade da constatação de prejuízos à indústria interna (ADAMS; DIRLAM, 1981, p. 95) contrariando frontalmente, assim, as regras do GATT.

Em suma, os países subdesenvolvidos argumentavam que o excessivo protecionismo à agricultura dos países desenvolvidos (aliado à erosão crescente do princípio da nação mais favorecida, por conta dos diversos arranjos de preferências comerciais parciais, acima mencionados) e às suas indústrias intensivas em mão de obra representavam uma clara inconsistência com o espírito do GATT, porque resultava em menos comércio e não em mais, como era o objetivo do Acordo Geral.

\section{As rodadas Kennedy e Tóquio, as conquistas das nações em desenvolvimento e o florescimento do novo protecionismo nas décadas de 1970 e 1980}

Foi somente a partir da sexta rodada de negociações do GATT - durante a Rodada Kennedy, a mais prolongada de todas as realizadas até então (iniciada em 1963 e concluída em 1967) que, finalmente, por pressões dos países subdesenvolvidos, o GATT começou a reconhecer as desigualdades estruturais entre países industrializados e em desenvolvimento, passando a introduzir, explicitamente, emendas ao Acordo Geral, contemplando algumas iniciativas importantes em favor das nações menos desenvolvidas.

A principal mudança ocorrida na estrutura do GATT foi a introdução da Parte IV, no Acordo Geral de 1947, que tratava especificamente do tema Comércio e Desenvolvimento (Trade and Development), mediante a incorporação, ao texto do Acordo, de um longo artigo, o XXXVI.

Partindo do reconhecimento de que "a elevação dos padrões de vida (...) era um objetivo particularmente urgente para as partes contratantes menos desenvolvidas" (letra a do parágrafo $1^{\circ}$ ), de que "as receitas dos países menos desenvolvidos podiam desempenhar um papel vital no seu desenvolvimento econômico" (letra b) e, por fim, de que "havia um crescente alargamento do gap entre os padrões de vida das nações em desenvolvimento e as outras” (letra c), o referido artigo XXXVI do GATT 
reconhecia a necessidade da "diversificação e da intensificação das atividades de processamento de bens primários e o desenvolvimento da indústria manufatureira” nos países em desenvolvimento (parágrafo $5^{\circ}$ ), e que, para que tal objetivo pudesse ser alcançado, as nações industrializadas deveriam facilitar o acesso desses bens nos seus mercados (WTO/GATT 1947).

O mecanismo a ser utilizado para se alcançar um maior incremento das exportações dos países menos desenvolvidos foi o reconhecimento, pela primeira vez no GATT, do direito da não-reciprocidade por parte desses países, nas suas relações com as nações industrializadas - direito que veio a constar oficialmente das regras do Acordo geral em 1966, um ano antes da finalização da Rodada Kennedy.

Todavia, a despeito da grande conquista por parte dos países em desenvolvimento em obterem o direito à não-reciprocidade (após quase vinte anos de existência do GATT), o art. XXXVI não tinha caráter impositivo para as partes contratantes (no caso, as nações industrializadas). No seu parágrafo $8^{\circ}$, o citado artigo apenas estabelecia que "as partes contratantes desenvolvidas não esperam reciprocidade pelos compromissos assumidos por elas nas negociações visando a reduzir ou eliminar os direitos alfandegários e outros obstáculos ao comércio das partes contratantes menos desenvolvidas" (WTO/GATT 1947). Firmava-se um compromisso, portanto, mas não uma obrigação.

Essas e outras pequenas mudanças, introduzidas no GATT após a Rodada Kennedy, trouxeram, na prática, poucas consequências para os países menos desenvolvidos, porque a aplicação do princípio da não-reciprocidade tinha alcance limitado e estava sujeita a inúmeras exceções. Ao deixar inteiramente a critério dos países industrializados a concessão de preferências, ou o tratamento mais favorecido às nações e, ao permitir a introdução de uma longa lista de exceções, os países industrializados continuaram limitando o livre acesso ou concedendo reduções tarifárias, apenas aos bens de seus interesses - que, em grande parte dos casos, não coincidiam com os dos países menos desenvolvidos.

Após a II UNCTAD, ainda presidida por Prebisch, e realizada em Nova Déli, na Índia, no ano de 1968, novas pressões foram feitas pelos países não-desenvolvidos propiciando a obtenção de algumas conquistas adicionais. Uma delas foi a criação, no ano de 1971, do Sistema Geral de Preferências (SGP) - um mecanismo que promovia a generalização de preferências comerciais aos países em desenvolvimento, além das concedidas dentro dos esquemas parciais de preferência (embora em condições menos favoráveis do que as concedidas pelos países da Europa às nações do ACP). Uma segunda conquista foi o aumento da participação dos países menos desenvolvidos nas negociações comerciais que se seguiram: a da Rodada Tóquio - última realizada antes da Rodada Uruguai, e que se estendeu entre 1973 e 1979.

Nessa rodada, agora com o envolvimento direto de 99 Estados, a grande maioria constituída de países subdesenvolvidos, não somente foi consagrado o direito dessas nações a participarem de sistemas de preferências comerciais sem a obrigação da reciprocidade, como também foi feita uma forte pressão para a introdução, nas pautas de negociações, de novos temas de interesse dos países menos desenvolvidos, 
sobretudo no que dizia respeito à redução ou à eliminação de barreiras não-tarifárias (ou barreiras implícitas), que estavam sendo crescentemente utilizadas pelas nações industrializadas, como substituto dos mecanismos tradicionais de restrição ao comércio, que eram as tarifas - as chamadas barreiras explícitas a importações.

Todavia, apesar de algumas conquistas alcançadas pelas nações menos desenvolvidas, Prebisch, escrevendo anos depois de ter-se desligado das suas atribuições como Secretário da UNCTAD, afirmava que as expressivas reduções tarifárias e a eliminação de restrições quantitativas ocorridas ao longo das várias negociações multilaterais do GATT, concentraram-se principalmente em bens tecnologicamente avançados, que estavam constantemente sofrendo inovações, o que tendia a ocorrer quase que exclusivamente nos países centrais (PREBISCH, 1984, p. 189). Prebisch concluía lamentando que, com relação aos bens nos quais a periferia poderia competir nos mercados do Primeiro Mundo, os países industrializados não haviam praticado uma política comercial verdadeiramente liberal. ${ }^{8}$

Com efeito, avaliações das rodadas de negociações do GATT mostram que as restrições tarifárias impostas pelas nações industrializadas caíram largamente entre 1947 e 1979, de mais de 50\%, em média, para níveis próximos ou abaixo dos 5\% (BHAGWATI, 1988).

Esse processo de liberalização ocorreu, de forma lenta e gradual, por meio de custosas negociações multilaterais em sete sucessivas rodadas do GATT, chegando-se a um consenso generalizado de que o mundo industrializado, ao final da Rodada Tóquio, em 1979, havia praticamente eliminado as antigas e mais tradicionais formas de protecionismo explícito.

Porém, a partir da década de 1970, ressurge uma nova tendência protecionista no Primeiro Mundo, com o aparecimento de significativos aumentos nas restrições ao comércio, diferentes das tradicionalmente praticadas até então. Enquanto as barreiras tarifárias continuavam caindo em níveis mínimos, emergiram, nas décadas de 70 e de 80, novas formas de proteção: as chamadas barreiras não-tarifárias, que constituíam formas mais sutis e mais veladas de discriminação contra importações e, talvez até por isso, mais eficazes. Exemplos de barreiras não-tarifárias eram, entre tantos, controles de qualidade, exigências de emissão de certificados de origem, inspeções pré-embarque, restrições voluntárias às exportações, barreiras técnicas, controles sanitários e ecológicos, direitos antidumping e subsídios à produção e às exportações.

Enfim, as diversas rodadas de negociações multilaterais praticamente conseguiram desmantelar o "velho protecionismo", mas o GATT não teve muito sucesso em evitar o florescimento do "novo protecionismo", e essa instituição foi acusada de ser até permissiva ou leniente em relação a essas práticas do Primeiro Mundo.

Esse novo protecionismo, como assinalava Prebisch - também chamado de "novo mercantilismo" - atingiu especialmente as nações do Terceiro Mundo, e particularmente aquelas que já haviam alcançado um grau maior de desenvolvimento, entre as quais o Brasil se enquadrava.

\footnotetext{
Ibid, p. 190.
} 
Especial registro deve ser feito ao fato de que, com o crescimento das exportações de manufaturados por alguns países do então chamado Terceiro Mundo, a partir dos anos 1970, a filosofia de ação do GATT passou a incorporar preocupações com um tipo de comércio que poderia ser capaz de provocar impactos desfavoráveis sobre alguns setores das economias das nações industrializadas - não importando se as dificuldades desses setores se devessem à ineficiência dos produtores domésticos e, menos ainda importando, os prejuízos causados aos consumidores desses países.

O fato é que, da sua visão de que os países desenvolvidos deveriam praticar sempre o livre comércio multilateral (e até mesmo unilateral), especialmente em relação às nações menos desenvolvidas, o próprio GATT começou a admitir que os países industrializados poderiam defender certos segmentos de suas economias quando ameaçados pela concorrência de importações - o caso dos chamados "setores sensíveis".

Vale ressaltar que, embora as negociações multilaterais do GATT tenham sido bem-sucedidas na área do comércio de produtos manufaturados, várias exceções foram aceitas por essa instituição. Muitas indústrias foram consideradas como "sensitivas e a merecerem status especial", e passíveis de enquadramento nas famosas escape clauses, que conferiam aos países industrializados o direito de se protegerem contra importações competitivas de manufaturas. A esse respeito, vários estudos mostram que os países desenvolvidos passaram a proteger mais intensamente suas indústrias intensivas de mão de obra não-qualificada - que são exatamente aquelas em que se situavam as vantagens comparativas dos países menos desenvolvidos, como os produtos da indústria têxtil, de vestuário e de confecções, os calçados, o aço e demais derivados siderúrgicos, produtos de plástico, alguns bens eletrônicos de consumo e os produtos da sua agroindústria. Esses estudos também revelavam que as concessões ou preferências comerciais dos países industrializados haviam sido mais generosas exatamente para os bens nos quais as indústrias dos países em desenvolvimento eram menos competitivas, ou seja, aquelas onde era claramente evidente a superioridade tecnológica das nações desenvolvidas (WILLIAMSON e MILNER,1991, p.333; ETHIER, 1988, p.216 e HINE, 1994, p. 265).

Além do mais, até mesmo algumas das importantes conquistas dos países menos desenvolvidos, alcançadas sobretudo durante as Rodadas Kennedy e Tóquio, começaram a ser desrespeitadas pelos países industrializados. Como já mencionado acima, havia sido acertado, ao final daquelas duas rodadas, a não-exigência de simetria de tratamento entre países industrializados e as nações do Terceiro Mundo. Após essas duas rodadas, porém, grande parte das concessões do Primeiro Mundo continuou sendo realizada em bases recíprocas e a partir da década de 80 - e especialmente durante o período em que se desenvolveram as negociações da Rodada Uruguai (1986-1993) - o GATT, por pressão dos países industrializados, passou, de novo, a permitir que a maioria das negociações entre os dois grupos de países ocorressem em bases de completa simetria e plena reciprocidade (REGO, 1994, p. 67-70; ABREU, 1994; MRE/BDE, 1994).

Muitos analistas dos próprios países industrializados indagavam o porquê de tanta atividade protecionista nesses países. Na verdade, por volta do início da segunda metade dos anos 1970 a produção industrial das nações menos desenvolvidas representava apenas cerca de $9 \%$ de toda a produção mundial e menos de $10 \%$ de todas 
as exportações manufatureiras do globo e essas exportações não atingiam sequer 1\% do consumo total de manufaturados dos países industrializados (HANSEN, 1981, p. 229). Além do mais, mesmo levando-se em conta que as exportações de manufaturados das nações menos desenvolvidas se concentravam em poucos itens, os principais produtos exportados ainda representavam, por volta do final da década de 1970, um reduzido percentual do consumo total nos países industrializados. Considerando-se o produto mais importante da pauta das exportações do Terceiro Mundo - os artigos da indústria têxtil e de confecções - os países em desenvolvimento forneciam menos de $8 \%$ do consumo total de confecções nos Estados Unidos, ao final dos anos 1970, e, somando-se confecções e produtos têxteis, esse percentual era ainda menor - da ordem de 4\% para os Estados Unidos, de 8\% para a Alemanha e de 2\% para a França (HANSEN, 1981, pp. 229-30).

A resposta a essas indagações reside no fato de que a liberalização comercial que ocorria ao longo das rodadas do GATT, durante as décadas de 1960 e 1970, havia afetado particularmente as indústrias manufatureiras tradicionais dos países industrializados, nas quais suas vantagens comparativas vinham experimentando sustentado declínio, por essa época. Como essas indústrias (têxteis, calçados, siderúrgicas, químicas, eletrônicas e agroindústrias, especialmente) haviam dado margem à formação de poderosas associações sindicalizadas, com grande capacidade de influência junto aos poderes legislativos e executivos de seus países, o resultado foi o de que, o aumento da concorrência estrangeira de produtos mais baratos - que representava uma ameaça potencial, ao emprego e ao nível da atividade produtiva nessas indústrias - provocou uma pressão crescente na direção de uma onda setorializada de fortes medidas protecionistas, impactando negativamente os países em desenvolvimento e, principalmente, os de grau intermediário de industrialização, como o Brasil (AMACHER, TOLLISON; WILLETT, 1981, p. 68).

Em suma, as relações comerciais dos países industrializados com os menos desenvolvidos e, de modo especial com a América Latina, se já não eram tão satisfatórias nos anos 1950 e 1960, sofreram um ponto de inflexão a partir dos anos 1970, assumindo uma característica cada vez mais discriminatória, tanto no que diz respeito à exportação de produtos manufaturados, quanto à de bens agrícolas e agroindustriais.

Mas, se os países menos desenvolvidos encontravam severas restrições às exportações de muitas das suas manufaturas para o mundo industrializado, na esfera agrícola eram crescentes, e talvez ainda maiores, as dificuldades do Terceiro Mundo em exportar os produtos da sua agricultura.

Vale relembrar, de início, que o setor agrícola esteve isento da disciplina do GATT praticamente desde o início da operação deste Acordo.

Durante as décadas de 1950 e 1960, a admissão de excepcionalidade do setor agrícola recebeu forte apoio dos Estados Unidos e de outros países industrializados, e, também, mecanismos sofisticados de suporte à renda dos agricultores foram amplamente criados nos Estados Unidos, nos países da Europa e no Japão.

O resultado não deixa de ser um tanto curioso: enquanto as nações industrializadas protegiam a sua agricultura, os países subdesenvolvidos protegiam as suas 
manufaturas - já que foi exatamente nessas duas décadas que se verificou o auge das políticas de industrialização via substituição de importações nos países do Terceiro Mundo. Vale lembrar, a esse respeito, que Prebisch e vários de seus contemporâneos da Comissão Econômica para a América Latina (CEPAL), justificavam as políticas passadas de introversão do crescimento de muitas nações subdesenvolvidas, e particularmente as da América Latina, exatamente por conta das dificuldades desses países extraírem, como fonte de seu desenvolvimento, tanto o aumento das exportações de commodities agrícolas quanto de manufaturas intensivas em mão de obra para as nações industrializadas (PREBISCH, 1964 e 1984).

As décadas de 1970 e 1980 testemunharam o fortalecimento ainda maior das políticas de proteção à agricultura pelos países desenvolvidos.

Desde a entrada em operação da Política Agrícola Comum (PAC) da União Europeia, em 1968, as negociações das rodadas do GATT sobre o comércio de bens agrícolas passaram a ser fonte de controvérsias insuperáveis, seja entre os europeus e as nações tipicamente exportadoras de bens primários, seja entre os primeiros e outros países industrializados, que também tinham fortes interesses no comércio exterior de bens agrícolas, como os Estados Unidos, o Canadá e a Austrália.

A importância conferida pelos burocratas da CEE ao setor agrícola era tamanha que a maior parte da legislação existente para regular o comércio da Comunidade dizia respeito à agricultura e nada menos de 3/4 de todos os recursos dos países membros eram destinados apenas aos programas de subsídios, de suporte de preços e de manutenção de uma renda mínima aos agricultores europeus (SWANN, 1990; MRE/ BDE, 1993).

Todos os outros países industrializados também protegiam largamente os seus agricultores. Nos Estados Unidos, a proteção do seu setor agrícola, que já era grande durante as décadas de 1960 e 1970, aumentou consideravelmente a partir dos anos 1980, com a promulgação pelo Congresso desse país, do Food Security Act de 1985 e com a criação do Export Enhancement Program, possibilitando que os agricultores norte-americanos passassem a competir mais agressivamente nos mercados internacionais de bens agrícolas (COUTINHO, 1994, p.22-24; THORSTENSEN, 1994).

A proteção à agricultura japonesa é quase anedótica. O Japão protegia tanto o seu setor agrícola, que o arroz - um dos principais bens agrícolas consumidos pelos japoneses - era produzido a um custo estimado em cerca de cinco a sete vezes o seu preço no mercado internacional.

Na verdade, é a agricultura o setor que sempre colocou as maiores dificuldades nas negociações internacionais de liberalização comercial.

O efeito dessa proteção excessiva foi o de fazer com que a agricultura produzisse enormes excedentes em praticamente todos os países desenvolvidos. É bom lembrar que após a 2a Guerra Mundial, os Estados Unidos e os países europeus tornaram-se, respectivamente, os primeiros maiores exportadores de bens agrícolas do mun$\mathrm{do}^{9}$. Isso aconteceu, deve-se frisar, não porque os agricultores desses países fossem

\footnotetext{
No final dos anos 80 a imprensa europeia fazia constantes referências aos "wine lakes", aos “milk oceans" e às
} 
especialmente mais eficientes do que os dos países em desenvolvimento, mas porque os seus governos subsidiavam generosamente a produção agrícola, tornando os preços dos bens agrícolas do mundo industrializado preços políticos e não preços de merca$\mathrm{do}^{10}$. Com esses preços políticos vigentes no $1^{\circ}$ Mundo, os países menos desenvolvidos tinham remotas chances de competir ${ }^{11}$.

A proteção à agricultura e a proliferação de barreiras não-tarifárias aplicadas pelos países desenvolvidos, assim como os arranjos de preferências comerciais acima mencionados, colocaram sérias dificuldades à expansão das exportações brasileiras.

Por outro lado, o Brasil reunia uma série de características que o tornava alvo privilegiado de medidas discriminatórias em relação às suas exportações: já era um país de grau de desenvolvimento intermediário (classificado como nação em desenvolvimento de renda alta, pelos critérios do Banco Mundial) - o que o tornava inelegível para se beneficiar de diversos esquemas de preferências comerciais; era um exportador importante de alguns bens manufaturados intensivos de mão de obra e que concorrem seriamente com a produção doméstica de velhas e tradicionais indústrias de países desenvolvidos; era usuário, até anos recentes, de um vasto arsenal de incentivos fiscais e subsídios a suas exportações (esquema de drawback, crédito prêmio de IPI e ICM, redução de IR, incentivos financeiros pré e pós embarques, isenções de impostos de importação, do IPI e ICMS, etc.) ${ }^{12}$ - o que fazia o país ser constantemente acusado de práticas desleais de comércio; era conhecido como país de enormes desigualdades sociais, por seus baixos salários e por fazer uso da mão de obra infantil (inclusive em setores exportadores) - o que alimentava alegações de praticar "dumping social”; gozava de low profile nos fóruns internacionais ligados à conservação ambiental, o que o tornava presa fácil dos movimentos ambientalistas em todo o mundo, sendo por isso penalizado com exigências especiais de natureza ecológica para várias de suas exportações; e tinha, até passado recente, uma das economias mais fechadas do mundo a importações, o que enfraquecia a posição negociadora do país nos fóruns internacionais de comércio, ao defender que outras nações praticassem políticas mais liberalizantes.

Não é de estranhar, assim, que o Brasil tivesse se tornado um dos países mais vitimados com a escalada de medidas protecionistas não-tarifárias que ocorreu em décadas passadas.

O cenário que se projetava para as décadas seguintes era o de uma escalada crescente de confrontos e desencontros na arena internacional. Dentro deste contexto,

\footnotetext{
"butter mountains" excedentes produzidos pelos agricultores da Comunidade (WILLIMANSON \& MILNER, 1991, p. 194).

${ }^{10}$ Estudos da CEE mostram que, durante os anos 1980, o custo de produção do trigo e da cevada nos países da Comunidade era 30 e $40 \%$ mais elevado do que os preços mundiais; o da carne era $90 \%$ mais alto e o da manteiga mais de $180 \%$ (SWANN, 1990, p. 219 e Tabela 20, p. 221).

11 Analistas da PAC europeia chegaram à conclusão de que se a UE praticasse efetivamente o livre comércio, esta região seria importadora da maioria dos bens agrícolas que ela produz e exporta (KRUGMAN e OBSTFELD, 1999, 4a ed. p. 199).

12 Estimativas governamentais revelam, por exemplo, que no ano de 1987, teriam sido transferidos apenas ao seu setor exportador industrial, aproximadamente 1,8\% do PIB brasileiro (BAUMANN, 1996, p. 12-14).
} 
a comunidade internacional, poucos anos após a Rodada Tóquio, encerrada no ano de 1979, já encarava como necessária mais outra rodada de negociações multilaterais, que se iniciou em 1986, após uma reunião de abertura na cidade de Punta del Leste, no Uruguai.

\section{Conclusões}

Após a Segunda Grande Guerra, a economia mundial presenciou enormes avanços nas iniciativas de liberalização do comércio internacional, registrando significativo declínio nas restrições tarifárias da parte dos países industrializados, assim como também de muitas nações em desenvolvimento. Ao longo de lentas e custosas negociações multilaterais em sete sucessivas rodadas promovidas sob a égide do GATT - da primeira de 1947 (Rodada Genebra) à última, concluída em 1979 (Rodada Tóquio), chegou-se à conclusão que o mundo industrializado parecia haver praticamente eliminado as antigas e mais tradicionais formas de protecionismo explícito.

Todavia, embora as diversas rodadas de negociações do GATT tenham, em larga medida, desmantelado o que passou a ser chamado de o "velho protecionismo", surgiu, simultaneamente à redução das tarifas alfandegárias, um conjunto de novas restrições ao comércio - as barreiras não-tarifárias - caracterizando o que veio a ser denominado de "novo protecionismo" do Primeiro Mundo, e que se manifestava por meio de formas mais veladas e mais sutis de discriminação contra importações.

Essas barreiras não-tarifárias passaram a afetar uma grande parcela do comércio mundial, atingindo de modo especial os países menos desenvolvidos e, particularmente, aqueles que já haviam alcançado estágio intermediário de industrialização, a exemplo do Brasil - porque tais barreiras se voltavam, em larga medida, para conter as exportações competitivas de produtos industrializados e agroindustriais intensivos em mão de obra dos países em desenvolvimento.

Em meados da década de 1980, com o início de mais uma Rodada, que veio a ser denominada Rodada Uruguai, a expectativa era a de que o mundo poderia vir a realizar um decidido avanço na direção de um sistema multilateral de negociações, incluindo uma redução significativa das barreiras não tarifárias, uma diminuição da proteção à agricultura pelos países desenvolvidos e um declínio da importância dos esquemas de preferências comerciais discriminatórios. Da parte dos países em desenvolvimento, por sua vez, seria exigido, como contrapartida, o abandono de políticas industriais protecionistas, um esforço crescente para a abertura de suas economias, o respeito ao direito de propriedade intelectual e certos requisitos relativos ao meio ambiente, a normas sociais e trabalhistas. 


\section{Referências}

ABREU, M.P.: O Brasil na Rodada Uruguai do GATT - 1982/1993. PUC, Rio de Janeiro 1994.

ADAMS, W. \& DIRLAM, J.B.: Concorrência Injusta no Comércio Internacional. In Institute for Contemporary Studies: Tarifas, Quotas e Comércio - A Política do Protecionismo. Zahar Editores S.A., Rio de Janeiro, 1981.

AMACHER, R.C., TOLLISON, R.D \& WILLETT, T.D. A Divergência entre a Teoria e a Prática. In Institute for Contemporary Studies: Tarifas, Quotas e Comércio - A Política do Protecionismo. Zahar Editores S.A., Rio de Janeiro, 1981.

BAUMANN, R.: (Org.) O Brasil e a Economia Global. Editora Campus, Rio de Janeiro, 1996.

. Uma Visão Econômica da Globalização. In Baumann, R.(Org.): O Brasil e a Economia Global. Editora Campus, Rio de Janeiro, 1996.

BHAGWATI, J. Protectionism. The MIT Press, Cambridge, Mass,1988.

BOLETIM de Diplomacia Econômica. Ministério das Relações Exteriores (BDE/MRE) Edição Especial sobre a Integração Europeia. o 14, fevereiro, Brasília, DF, 1993.

: (BDE/MRE): O GATT e a Rodada Uruguai. Brasília, Ministério das Relações Exteriores, Brasília, DF, nº18, agosto, 1994.

COUTINHO, P. C. (Org.): O Impacto de Políticas de Suporte à Agricultura sobre a Economia Brasileira: Uma Proposta de Quantificação. IPEA, Relatórios de Pesquisa, n 29, Brasília, DF, nov. 1994.

HANSEN, R. D.: O Comércio, os Países em Desenvolvimento e as Relações Norte-Sul. In Institute for Contemporary Studies: Tarifas, Quotas e Comércio - A Política do Protecionismo. Zahar Editores S.A., Rio de Janeiro, 1981.

HINE, R. C.: International Economic Integration. In Greenaway D. \& Alan Winters, L. (Eds.): Surveys in International Trade, Blackwell, Oxford, 1994.

JOHNSON, H. G.: Economic Policies Toward Less Developed Countries. Frederick A. Praeger, Pusblishers, New York, 1968.

KRUGMAN, P. R. \& OBSTFELD, M.: Economia Internacional - Teoria e Política. Makron Books do Brasil Editora Ltda., São Paulo, SP, 4ª Ed.,1999.

LAIRD, S.: WTO Rules and Good Practice on Export Policy. World Trade Organization, Staff Working Paper, Genebra, manuscript, 1997.

MEYER, M.G. e SEERS D. (Eds.): Pioneers in Development. World Bank/Oxford University Press, Oxford, 1984 
PREBISCH, R.: Five Stages in My Thinking on Development. In Meyer, M.G. e Seers D. (Eds.): Pioneers in Development. World Bank/Oxford University Press, Oxford, 1984.

Modern International Economics, : Towards a New Trade Policy for Development. Report by the Secretary-General of the United Nations Conference on Trade and Development-UNCTAD, United Nations, New York, 1964.

REGO, T. E. G.: Globalização e Regionalismo. In BDE/MRE: O GATT e a Rodada Uruguai. No 18, agosto, Brasília, DF, 1994.

SWANN, D.: The Economics of the Common Market. Penguin Books, $6^{\text {th }}$ Edition, Londres, 1990.

THORSTENSEN, V. et al.: O Brasil Frente a um Mundo Dividido em Blocos. Instituto Sul-Norte de Política Econômica e Relações Internacionais. Ed. Nobel, São Paulo, 1994.

WILLIAMSON, J. e MILNER, C.: The World Economy - A Texbook in International Economics. Harvester Wheatscheaf, Londres/New York, 1991.

WORLD BANK: World Economic Report, Genebra, 2015.

WTO/GATT GATT 1947 (amended through 1966), Genebra, 1994.

WTO/GATT: The Agreement on Textiles and Clothing (ATC), Genebra 1994. 